\title{
Ciganos nacionais
}

\author{
National Gypsies
}

\section{Florencia Ferrari}

Universidade de São Paulo, Brasil

E-mail: florferrari@gmail.com

\section{RESUMO}

Este artigo é um ensaio sobre o lugar do cigano em obras literárias produzidas pelo 0 cidente. Se 0 imaginário ocidental vê no cigano um estrangeiro, um ser ambíguo, do qual sentetemor ou fascínio conforme a situação, aqui se arrisca um deslocamento do recorte, chamando a atenção para a apropriação da figura do cigano na construção da identidade de duas nações: o Brasil e a Espanha. Servindo-se dessa figura de forma muito diversa, autores dos dois países transformaram o conteúdo da representação do cigano em um valor nacional próprio, comprovando, por outro lado, a ambigüidade e plasticidade da imagem do cigano.

Palavras-chave: Cigano, literatura, representação, Espanha, Brasil.

\section{ABST RACT}

This article is an essay about the place of Gypsy people in literary pieces produced by the Western C ivilization. If the W estern's imaginary sees the $G$ ypsies as foreigners as much as an ambiguous beings, whom, depending on the situation, they fear or are fascinated with, here we takethe chance to displace this interpretation, underlining the assimilation of the gipsy figure in the identity building process of two nations: Brazil and Spain. Using this image in assorted ways, authors from both countries restore the gypsy's representation content into a national value itself, proving, on the other hand, the ambiguity and plasticity comprised in the gypsy's image.

Keywords: Gypsy, literature, representation, Spain, Brazil.

* Este artigo é uma adaptação do capítulo iv de minha dissertação de mestrado (Ferrari, 2002). 0 tema do capítulo oferece um contraponto à argumentação da tese, cujo ponto central é busca de um sentido para distintas representações do cigano em diversas obras da literatura ocidental. Em síntese, busca-se ali a resposta para a seguinte questão: 0 que a adivinhação, 0 nomadismo, o roubo, a sedução têm em comum para o olhar ocidental? 


\section{RESU MEN}

Este artículo es un ensayo sobre el lugar del gitano en obras literarias producidas por occidente. Si el imaginario occidental ve en el gitano un extranjero, un ser ambiguo, del cual uno siente temor o fascinación según la situación, aquí se arriesga una interpretación desde otro punto de vista, llamando la atención para la apropiación de la figura del gitano en la construcción de la identidad de dos naciones: Brasil y España. Sirviéndose de esa figura de forma muy diversa, autores de los dos países han logrado tran sformar el contenido de la representación del gitano en un valor nacional propio.

Palabras claves: Gitano, literatura, representación, Brasil, España.

Recibido: 26-04-2006. Aceptado: 16-05-2006.

A NECESSID ADE do contato com um outro para descobrir a si mesmo éum lugar-comum do exercício da antropologia. Tomamos consciência denossa cultura no instante mesmo em que nos defrontamos com outra cultura. $\mathrm{Ou}$ ainda, em outros termos, ao inventarmos outra cultura, inventamos simultaneamente a nossa. Esse procedimento de contraste, contradição e reflexão permite, em determinadas circunstâncias, afirmações de identidades por oposição, e também por semelhança.

N o estudo de representações do cigano em obras literárias ocidentais ${ }^{1}$, busquei extrair um sentido que fosse ao mesmo tempo o mais reduzido eabrangente, que desse a explicação mais geral possível. Pude levantar de cabo a rabo do 0 cidente ${ }^{2}$ um imaginário do cigano como um estrangeiro, à margem, cercado de mistério. Entretando, não éa exclusão que marca o lugar do cigano no imaginário ocidental, mas antes a ambigüidade que o envolve. É o "ir além e voltar" que Ginzburg atribui às bruxas e que também se associa ao cigano o que faz deste um personagem sedutor, porém temido.

Esse imaginário de longa duração sobre o cigano deve ser tomado aqui como fundo, de onde as construções particulares tiram material para em seguida dar forma a outro pensamento. A idéia de que os ciganos podem ser vistos ao mesmo tempo como estrangeiros e como protótipo de uma identidade nacional parece à primeira vista descabida, ou contraditória. N o entanto, é possível pensar em ao menos dois casos concretos em que o imaginário hegemônico é tensionado por casos particulares. Trata-se talvez de uma mudança de perspecti-

${ }^{1}$ Ver Ferrari (2002).

${ }^{2} 0$ O cidente deve ser tomado aqui não como área geográfica ou como aglomerado de nações, mas como um conjunto de idéias, um discurso. A extensão referese, portanto, não a um lugar mas ao leque de representações. 
va: quando se olha do centro para "fora", os ciganos são vistos no limite da fronteira; cabe refletir então sob que perspectiva o cigano torna-se símbolo do nacional. Pois, conforme a perspectiva, o recorte e a realidade que dele decorre se alteram. $\mathrm{N}$ ão se trata de negar o ponto de vista geral, mas de apontar sua parcialidade.

A literatura é um bom campo para experimentar essas alterações de escala. D e modo geral, a presença de ciganosé sempresecundária, pontual, casual. M as esta é, justamente, uma posição específica, pois sua constância e proliferação como elemento menor é em si mesmo significante. É como detal he que semostra revelador de algo ocultado, subliminar, uma presença que age "contra" o que é posto no centro da cena.

Vejamos o que nos diz a literatura. Proponho analisar de perto dois casos: 0 Brasil e a Espanha. As literaturas produzidas nestes países se apresentam como contínuas sob a perspectiva da representação do cigano como outro, marginal, ambíguo, trickster; e descontínuas sob a perspectiva de uma representação que imagina uma identidade nacional. Aqui, dedicarei a atenção à última.

U ma primeira abordagem volta-se ao contexto brasileiro. Como o cigano pode ser lido na chave da identidade nacional brasileira? Basearei-me na análise já realizada com propriedade por Antonio C andido sobre a "dialética da malandragem", para então refletir sobre o papel do cigano dentro da argumentação que 0 autor propõe. Adotarei suas premissas e demonstrações para situar os ciganos no campo semântico do que o autor chama de "malandro".

0 segundo caso é decorrente da efervescência de alusões e referências ao contexto espanhol. 0 cigano conquistou ali um lugar singular, tanto aos ol hos dos espanhóis que se valeram deles para afirmar uma identidade própria, como aos olhos do restante do mundo, que identificou na Andaluzia um foco de ciganidade específico, ligado à música e à dança. A partir de representações literárias, pode-se efetivamente aferir uma continuidade identitária entre ciganos e Espanha. N esse sentido, será interessante apreciar a representação dos ciganos na literatura do ponto de vista da "nacionalidade", isto é, como uma tentativa de forjar uma identidade nacional.

\section{A. A M ALAN D RAGEM CIGANA}

Em famoso ensaio de crítica literária escrito originalmenteem 1970, “Dialética da mal andragem", Antonio C andido propõe uma nova leitura do romance M e mórias de um sargento de milícias, de M anuel Antônio de Almeida - analisado por muitos autores (José Veríssimo [1894], M ário de Andrade [1941], Darcy D amasceno [1956])- , buscando desvendar a natureza da impressão de real ismo 
passada pelo romance. Afastando interpretações que viam nele um romance de costumes, ou um estilo picaresco, Antonio Candido mostra como a obra de Antônio de Almeida manifesta o real ismo sob uma modalidadepeculiar. Embora L eonardo, o protagonista, se assemelhe em vários aspectos aos pícaros espanhóis (de origem humilde, amável, risonho, vivendo ao sabor da sorte), faltaIhe um traço básico do pícaro típico, a saber, o choque áspero com a realidade: Leonardo nada aprende com a experiência. Em lugar do pícaro, C andido sugere chamá-lo malandro, ou melhor, "o primeiro grande malandro que entra na novelística brasileira” (Candido, [1970] 1993: 25). A astúcia pela astúcia define a gratuidade de suas ações e se soma a dois traços marcantes da atuação tanto de Leonardo pai como de Leonardo filho, cuja síntese encontra materialidade na figura do trickster; são eles "a tolice, que afinal se revela salvadora, ea esperteza, que muitas vezes redunda em desastre, ao menos provisório" (idem: 27). A alegoria do trickster, como ente que oscila entre a tolice e a esperteza, a salvação e 0 desastre, será fundamental na interpretação da malandragem que atua nessa obra.

Tendo por base essas reflexões, Antonio C andido propõe que a integridade, etal vez o segredo da força e projeção no tempo, da obra de M anuel Antônio de Almeida se dá pela associação entre dois planos, um voluntário - a representação de costumes e cenas do Rio de Janeiro de uma determinada época- e outro em grande medida involuntário - baseado na dinâmica social do Brasil na primeira metade do século XIX. Entretanto, não se trata aqui de uma reprodução da realidade social, pois, lembra o autor, uma obra literária por mais realista que se pretenda jamais deve ser tomada como documento, em último caso, pode ser pensada como uma testemunha, que exige uma subjetividade. A relação que a literatura estabelece com a realidade pode ser arbitrária e distorcida, estando livre para inverter, suprimir ou agregar elementos ao seu bel prazer. 0 s elementos sociais não devem, portanto, ser buscados na superfície da obra, mas na própria constituição de sua estrutura. $D$ aí o elemento externo importar na medida em que se torna interno. Assim, o realismo de M emórias de um sargento de milícias, explícito no plano voluntário, que refaz um cenário de época, se firma de fato no plano involuntário, pela correlação que a estrutura do romance estabelece com a estrutura social.

0 procedimento que aciona uma redução estrutural dos dados externos permite desenhar uma dinâmica própria do livro, definida pelo autor como a "dialética entre a ordem ea desordem". Esta atua como um princípio estrutural, manifestado nas relações humanas que constituem o romance. 0 sistema de relações dos personagens aponta para: "1) a construção, na sociedade descrita, de uma ordem comunicando-se com uma desordem que a cerca de todos os lados; 2) a sua correspondência profunda a certos aspectos assumidos pela rela- 
ção entre a ordem e a desordem na sociedade brasileira da primeira metade do século XIX" (idem: 36). 0 autor cria uma gangorra que balança entre os dois pólos ordem/desordem, a partir da construção dos personagens: 0 pai vacila entre sua posição de oficial de justiça e seu amor transtornado por uma cigana; Leonardo, entre 0 amor de Luisinha - que representa a ordem, o casamento, a herança-, e o de Vidinha - a desordem, o prazer, o amor sem obrigações etc.; 0 major Vidigal expressa tal oscilação em seu corpo, quando é pego vestido com a casaca do uniforme, na parte superior, e seminu, de calção etamancos, na parte inferior. Esse jogo dialético se articula solidamente no romance e age como correspondente do que se manifestava na sociedade daquele tempo. D essa sorte, não éo uso de informações concretas que produz na ficção o senso da realidade, mas o que está por trás deles, isto é, o mecanismo que faz a sociedade e a ficção funcionar.

M as então, como entram os ciganos nesta obra e nesta análise? 0 romance, em queo protagonista éidentificado por Antonio C andido como um trickster e é visto como representativo do mecanismo da sociedade brasileira, por coincidência, ou não, conta com a presença de ciganos em distintos momentos. Em um primeiro nível mais superficial, nota-se que o cigano é um entre outros "tipos sociais" da época em que se passa o romance, fato que pode ser comprovado pela documentação oficial e as descrições deixadas pelos viajantes. A obra se mostra particularmente preocupada com revelar fatos da realidade histórica sobre os ciganos, como quando comenta a sua numerosa chegada ao Rio de J aneiro do século XIX3 , e em seguida a ocupação das imediações do Largo do Rossio. M anuel Antônio de Almeida faz uso de descrições etnográficas das vestimentas e adornos das ciganas, das festas e dos costumes dos ciganos, de resto, como faz com cada detal he de toda a narrativa. M as o lugar deles nessa obra, a meu ver, não se restringe a tal aspecto "externo". D eve-se procurar saber em que medida ele interage com o princípio dialético que dá peculiaridade ao romance.

D e uma maneira geral, as distintas aparições de ciganos no romance de Antonio de Almeida são secundárias para o enredo principal. Funcionam, assim, como detalhes que reforçam 0 argumento da narrativa, centrada sobre o personagem Leonardo. Logo no início (capítulo 4), Leonardo Pataca (pai do protagonista) fora a um velho caboclo para "tomar fortuna" e remediar o sofrimento queo amor a uma cigana Ihe causava: " $N$ ão Ihefora difícil conquistar a posse do

\footnotetext{
${ }^{3}$ Sobre os ciganos residentes no Rio de Janeiro, no início do século XIX, cogita-se que "quatrocentos ciganos formavam uma comunidade na periferia sul da cidade e outro grupo vivia dentro da cidade em torno da Rua dos Ciganos, Campo de Sant-'Anna e o mercado de escravos da cidade" (D onovan, 1992: 43 apud Teixeira, 1999).
} 
adorado objeto, porém a fidelidade, a unidade no gozo, que era o que sua al ma aspirava, isso não o pudera conseguir: a cigana tinha pouco mais ou menos sido feita no mesmo molde da saloia"4. Seguindo o romance, mais adiante (capítulo 6), um trecho apresenta a chegada da "praga dos ciganos".

Com os emigrados de Portugal veio também para o Brasil a praga dos ciganos. Gente ociosa e de poucos escrúpulos, ganharam eles aqui reputação bem merecida dos mais refinados velhacos ninguém que tivesse juízo se metia com eles em negócios, porque tinha certeza de levar carolo. A poesia de seus costumes e de suas crenças, de que muito se fala, deixaram-na da outra banda do oceano; para cá só trouxeram maus hábitos, esperteza evelhacaria [... ]. Viviam em quase completa ociosidade; não tinham noite sem festa. M oravam ordinariamente um pouco arredados das ruas populares, e viviam em plena liberdade. As muIheres trajavam com certo luxo relativo aos seus haveres: usavam muito de rendas e fitas; davam preferência a tudo quanto era encarnado, e nenhuma delas dispensava pelo menos um cordão de ouro ao pescoço; os homens não tinham outra distinção mais do que alguns traços fisionômicos particulares que os faziam conhecidos. 0 s dois meninos com quem o pequeno fugitivo [Leonardo] travara amizade, pertenciam a uma família dessa gente que morava no Largo do Rossio, lugar que tinha por isso até algum tempo o nome de Campo dos Ciganos.

[... ] como de costume, havia festa de ciganos (e este costume ainda hoje se conserva); faziam, dissemos, festa todos os dias, porém motivavam-na sempre. H oje era um batizado, amanhã um casamento, agora anos deste, logo anos daquele, festa deste, festa daquele santo. $\mathrm{N}$ a noite de que tratamos havia um oratório armado, e festejava-se um santo de devoção; não lhe sabemos o nome (Antônio de Almeida, [1855] 1998: 29-30, grifos meus)5.

E ainda, a cigana que enamorara Leonardo pai volta à cena, quando este descobre que quem o substituíra fora o reverendo mestre-de-cerimônia da Sé:

Um dia que a pilhou de jeito à janela [Leonardo Pataca] abordou-a, e começou ex abrupto a falar-Ihe deste modo:

-Você estájá em vida no inferno!... pois logo um padre?!..

A cigana interrompeu- 0 :

- $\mathrm{H}$ avia muitos meirinhos para escolher, mas nenhum me agradou...

\footnotetext{
${ }^{4}$ Refere-se à portuguesa M aria, que o enganara com outro homem. "Saloio" contém essa dupla acepção, segundo dicionário H ouaiss (2001): 1. que é dos arredores de Lisboa; 5. diz-se de ou indivíduo que revela falta de civilidade, de traquejo social ou de bom gosto; 6 . indivíduo que procede com manha ou velhacaria.

${ }^{5} 0$ primeiro personagem cigano dessa história é, na verdade, uma mulher por quem se apaixona Leonardo. Só há uma referência: ela troca L eonardo por outro homem.
} 
-M as você está cometendo um pecado mortal... está deitando sua alma a perder...

- H omem, sabe que mais? Você para pregador não serve, não tem jeito... eu, como estou, estou muito bem; não medei bem com os meirinhos, eu nasci pra coisa melhor... [... ]

0 Leonardo compreendeu que falando-Ihe do inferno e em castigos da outra vida nada arranjava, edecidiu dar-Iheo castigo mesmo nesta vida (idem).

D ias depois, comemorava-se o aniversário da cigana; Leonardo armou uma confusão atraindo a atenção do M ajor Vidigal, que acabou flagrando o mestredecerimônias "em ceroulas curtas e largas, de meias pretas, sapatos de fivela, e solidéu à cabeça".

Antes de anal isar como o cigano pode ser entendido a partir da dialética da ordem/desordem, presente no romance como um todo, será importante explicitar esta representação como uma versão das representações possíveis do imaginário ocidental, as quais, por sua vez, são passíveis de uma leitura euma ressignificação locais. Em primeiro lugar, identifica-se a presença do imaginário inquisitorial ${ }^{6}$ tanto na discussão entre Leonardo e a cigana, em que o primeiro pragueja que, pelos pecados cometidos com um padre, ela viveria no inferno - cenário já conhecido de associação à cigana. A mulher cigana, como al hures, detém o poder da sedução - aliás, tão forte que é capaz de conquistar o padre- , e este se aproxima, não raro, aos poderes do diabo.

Por outro lado, as relações comerciais dos brasileiros com os ciganos são marcadas por suas típicas artimanhas e enganos, causando extremo desconforto aos locais. Tais casos expressam, também como versões, o imaginário sobre 0 roubo e o comércio. A alusão ao espetáculo, presente no imaginário ocidental com figuras como Esmeralda de Victor $\mathrm{H}$ ugo e Carmen de M erimée se dá em dois momentos, quando se supõe "a poesia de seus costumes e crenças" deixada do outro lado do oceano, e nas inúmeras festas com músicas e danças, que, no entanto, são vistas como "ociosidade" enão com o fascínio, tal como encontrado em outros lugares. Tem-se ainda nesta obra a distinção entre as representações feminina e masculina dos ciganos; de um lado a sedução, explicitamente aquela em que se encanta mas não se entrega, e também próxima à representação da prostituta; e de outro, a "malandragem" no negócio.

Partes de um imaginário de longa duração, estas representações admitem, contudo, uma interpretação local, brasileira, que, aproximada à análise de An-

${ }^{6} \mathrm{O}$ Tribunal do Santo 0 fício da Inquisição, instituição criada no final do século XV empreendeu uma radical perseguição a hereges e a mulheres consideradas bruxas. As ciganas foram alvo particularmente privilegiado, reforçando a associação estreita destas com a feitiçaria e um acesso privilegiado ao além. 
tonio C andido, permite compreender o lugar do cigano no romance e na repre sentação da sociedade brasileira desse período. No contexto do 0 cidente, 0 cigano ocupou um papel liminar que lhe conferia ambigüidade. Resta agora esclarecer de que maneira essa liminaridade se atualiza na dinâmica do romance. Esta transposição, parece-me, deve ser feita estruturalmente, isto é, procurando correspondência entre as relações que o cigano estabelece nas representações ocidentais e as relações que dão sentido ao romance.

0 elemento cigano tem um papel claro a desempenhar nessa narrativa movida pela oscilação entre a ordem ea desordem. 0 s ciganos parecem alimentar 0 motor da máquina da desordem em relação à ordem. Eles chegam para desequilibrar um statusquo, fazendo uso dos atributos que os caracterizam. A vel hacaria e a esperteza, neste contexto, podem ser equiparados à malandragem que está no horizonte das ações do protagonista. A cigana, por sua vez, se vale de suas qualidades femininas para romper com a harmonia das posições representadas pelos personagen que seduz e, com isso, também subverte a ordem. 0 s ciganos contribuem, desse modo, para reforçar o lugar de intermediário social que 0 próprio protagonista ocupa. A ambigüidade representada por el es funciona como um dos catalisadores da ambigüidade entre ordem e desordem da sociedade em questão, representada pelo malandro.

Esta constatação acena para uma nova chave interpretativa com relação aos ciganos no seio do cenário brasileiro. Se é possível afirmar em um plano mais global que o cigano é um mediador, em certas circunstâncias no entanto, esta qualidade toma uma conotação local, e o cigano pode ser pensado como um análogo do malandro, um intermediário específico da sociedade brasileira. 0 malandro, porém, não éum personagem isolado na obra deAntônio deAlmeida. Ele trilha uma longa trajetória na literatura brasileira e tal vez sua manifestação mais marcante seja na personagem M acunaíma, da obra homônima de $M$ ário deAndrade[1928] ${ }^{7}$. Poder-se-ia arriscar uma aproximação entre as extraordinárias viagens de $M$ acunaíma e a idéia de um nomadismo extremo permeado da diversidade que o contato com distintas culturas proporciona; mas não tendo por ora dedicado suficiente atenção ao romance, deixo esta imagem como sugestão para outro estudo. Assim, permanecerei com o conjunto de obras selecionado, propondo uma leitura interessada de um trecho de 0 cortiço de Aluísio Azevedo que pode corroborar a associação entre o cigano e um mediador tipicamente brasileiro.

\footnotetext{
${ }^{7}$ A bibliografia sobre o malandro é extensa. Entre os principais autores que tratam dela, além de Antonio Candido e Lilia Schwarcz, destaca-se Roberto D aM atta, com o livro Carnavais, malandros e heróis[1978].
} 
N esse romance de 1890, a portuguesa Piedade acusa a mulata Rita de "cigana", sugerindo com isto uma atitude libertina. O ra, sem entrar na extensa discussão racial inaugurada pelas teorias evolucionistas, deterministas e racialistas, do final do século XIX, pode-se sugerir que o mulato ocupa uma posição intermediária e por isso mesmo ambígua no pensamento brasileiro. A mestiçagem, queaté o início do século XX mostrava-seum verdadeiro problema para as elites do Brasil - da medicina ao direito, não houve quem deixasse de opinar sobre seus prejuízos à nação- ganha uma nova versão, não mais detratora, mas moral e nacional na "malandragem". N as personagens de M acunaíma ou de Zé C arioca, o papagaio de Alô ami gos [1942], da D isney, se reconhecia "uma espécie de síntese local, ou ao menos uma boa imagem a ser exportada" (Schwarcz, 1995: 51). A busca de uma nova identidade nacional, outrora associada ao indigenismo romântico forjado pelas el ites que cercavam $D$. Pedro II, foi empreendida pelo governo do Estado N ovo, que encontrava no mestiço um ícone potencial. Lilia Schwarcz mostra como nesse período se oficial izaram elementos culturais antes repreendidos: "Afinal, o samba, a capoeira, o candomblé, a mulata eo malandro carioca são, em graus diferentes, transformados em ícones nacionais, produzidos e reproduzidos interna e externamente" (idem: 58).

Entre o malandro Leonardo ea mulata Rita há, portanto, um pano de fundo comum. Ambos representam personagens ambíguos e, ao mesmo tempo, servem potencialmente de signo à construção de uma identidade própria brasileira. Sob esse aspecto, parece interessante pensar a aproximação do cigano a tais personagens. Ao que tudo indica, o cigano, que no plano mais geral é um mediador, desempenha aqui a mesma posição estrutural, impregnada, contudo, de um conteúdo particular. Contribuindo para a construção de um universo simbólico ambíguo, o cigano é apropriado para pensar a identidade brasileira.

Sem deixar de ser um índice de alteridade, no Brasil, pode-se pensar no cigano como portador de um status simbólico distinto, justamente pelo fato de a representação da identidade brasileira ter por base a alteridade negra e indígena em relação ao branco europeu. Assim, foi possível vêlo na chave local junto ao malandro e à mulata, intermediários sociais que são chamados a representar essa sociedade plural. É claro que não se pretendeaqui concluir que o cigano na realidadeéícone da sociedade brasileira, pois estaríamos tomando ao pé da letra o que se mostra em sentido figurado. $N$ ão é disso que se trata. Diferente do índio no romantismo, o cigano é um cúmplice da estrela principal, o malandro, o mestiço ou a mulata. A idéia aqui, portanto, é antes nuançar a representação universal do estrangeiro genérico, e mostrar como o elemento estrangeiro pode ser real ocado e ganhar novas significações, passando a fazer parte de um novo universo simbólico local. Com efeito, creio que o cigano permanece nessas re- 
presentações como alteridade, mas por vezes para afirmá-la no interior de uma identidade, conforme se vê no caso brasileiro, em determinado contexto.

A analogia com a mulata e o malandro, nos anos 1930 e 1940, sugere ainda uma reflexão que não se poderá desenvolver aqui, mas é fundamental têla presente. A proximar essas figuras como elementos nacionais não as torna menos suscetíveis de preconceitos e medidas sociais efetivas em seu cotidiano. N ão é preciso alongar demonstrações para dizer que o preconceito racial opera habitual mente em relação ao negro eao mulato, e algo similar, com as devidas proporções, ocorre em relação ao cigano. H á uma série de estudos sobre as discriminações sofridas pelos ciganos não só no Brasil, e as difíceis condições de vida que enfrentam, muitas vezes, por não se alinharem à oficialidade da moradia, da escolarização, da língua, etc. ${ }^{8} M$ as, esta é uma questão posta em outro plano, e não solapa o quese pôde apurar no nível do imaginário. Ao contrário, creio que o mapeamento do imaginário é uma maneira poderosa de mostrar como foi se criando, e a força que resultou ter, um determinado conjunto de idéias sobre os ciganos, por meio das quais o 0 cidente continua operando até os dias atuais no cotidiano com eles. Sem o intuito único de denunciar as medidas de repressão aos ciganos, este texto parece-me imerso nessa questão política, e ajuda a compreender o mal-estar que esses grupos nômades causam aos ocidentais.

\section{B. AN D ALUZIA, QUAND 00 NÔ MADE CRIA RAÍZES}

D iferentemente do exemplo brasileiro, o cigano na Espanha não aparece como um apêndice que dá reforço simbólico para a construção de uma identidade nacional centrada em outra figura; ali ele ocupou o centro do palco efoi tomado por ícone nacional. À semelhança do mulato e do malandro Zé C arioca no B rasil deum certo período, o cigano é reconhecido externamente como símbolo da identidade espanhola e, mais especificamente, andaluza. A Espanha aparece não raro como uma referência para caracterizar seja a proveniência dos ciganos, seja o cenário em que a ação se desenrola. Todo o romance de M erimée se passa na Andaluzia e C armen, sua protagonista, constituirá, com a adaptação de Bizet para ópera [1875], a síntese do imaginário feminino espanhol. Esmeralda, de Victor H ugo, e as ciganas de Gil Vicente são também ciganas andaluzas em viagem. Em 0 guarani [1857], de osé de Alencar, há uma al usão à procedência certa dos ciganos: "sobre uma cômoda, via-se uma dessas guitarras espanholas que os ciganos introduziram no Brasil quando expulsos de Portugal". O s versos

\footnotetext{
${ }^{8} \mathrm{Cf}$., entre outros, Cortesão \& Pinto, 1995.
} 
tardios de João Cabral de M elo N eto de Sevilha andando (1987-93) eAndando Sevilha (1987-9) fazem explícita referência ao universo cigano que seimiscui no andaluz.

I gualmente, o cenário da cigana no centro da roda, reconstruído por Raduan $N$ assar em Lavoura arcaica [1975], remete ao contexto espanhol, ao imaginar nos gestos da personagem as palmas e as castanholas próprias do flamenco. Ao que parece aquela "célula" que se identificou em diversos textos, em que há uma mulher cigana que dança e canta e, ao seu redor, um círculo de homens "enfeitiçado" por ela, é, em boa parte das vezes, uma alusão ao flamenco e, portanto, à Andaluzia. M as em que consiste esse universo simbólico andaluz ligado à música e aos ciganos?

A relação com a música é um traço encontrado entre os ciganos também no Leste Europeu, onde, como já foi dito, incorporaram estilos musicais dos lugares em que passaram. 0 que hoje é conhecido como flamen $c 0^{9}$ tem sua origem no cante jondo, um estilo musical que se formou na Andaluzia com a colaboração de elementos do canto litúrgico bizantino e da invasão árabe em 711 -e também possivelmente da música hebraica-, amalgamados pelos ciganos (Gibson, 1998: 182; Vaux de Foletier, 1970: 135). A siguiriya (um dos três estilos de cante jondo) constitui, segundo M iguel de Falla - primeiro estudioso do estilo- , a forma arquetípica do gênero, "o fio que nos une ao 0 riente impenetrável" (apud Gibson, 1998: idem). Segundo Bernard Leblon (1990), embora usando elementos da cultura local, os ciganos parecem preferir instrumentos afins ao padrão instrumental da Í ndia e de outras terras do leste ${ }^{10}$.

$M$ as foi o poeta espanhol Federico $G$ arcía Lorca, amigo deFalla, quem colaborou definitivamente para a associação do universo artístico do cigano à Andaluzia e ao flamenco, com a obra Romancero gitano. Considerado o livro "mais lido, mais recitado, mais analisado e mais célebre de toda a literatura espanhola" (G ibson, 1998: 214) ${ }^{11}$, o Romancero gitano, escrito entre 1924 e1927, apresen-

\footnotetext{
${ }^{9}$ Em Carmen, há uma passagem em que a personagem diz "[... ] Allons, il y a remède a tout, quand on a pour bonne amie une flamande de Rome" (M erimée, [1845] 1960: 51), na qual 0 autor acrescenta uma nota de rodapé: "Flamenca de Roma. Gíria que designa as bohémiennes, Roma não quer dizer a cidade eterna, mas a nação dos Romi ou das pessoas casadas, nome dado aos bohémiens. O s primeiros ciganos vistos na Espanha vinham provavelmente dos Países Baixos, de onde veio o nome deFlamands" (id.:ibid., nota 35). D aí a origem do vocábulo flamenco.

${ }^{10} 0$ autor argumenta que as músicas ciganas em diferentes países têm mais elementos em comum do que aparentam eque os aspectos recorrentes são freqüentemente associados à música oriental.

${ }^{11} \mathrm{~N}$ ão se fará justiça à importância e complexidade da obra neste en saio, pois será necessário reduzi-la a uns poucos aspectos diretamente relacionados a esta investigação. Para melhor
} 
ta uma série de 18 romances" que resulta num "canto andaluz, no qual os ciganos servem de estribilho" (Lorca apud Gibson, 1998: 212). Por meio da alternância e da interação do cotidiano e de uma dimensão mítica, episódios como 0 falecimento de uma criança, o choro das ciganas, aluta entre ciganos, a eminente morte do cigano na casa do pai de sua amada, a possessão de uma cigana, a conquista amorosa, 0 desencanto e a solidão angustiada, o ritual na rua, 0 anúncio da concepção, a contraposição entre o cigano e a guarda civil, o oráculo e as superstições, etc., enfim, uma multiplicidade de elementos da cultura são tecidos, resultando numa visão bastante complexa do arcabouço cultural desses ciganos. M as não cabe aqui alongar uma análise da obra; esta interessa na medida em que evidencia o esforço de Lorca, no início do século XX, de enaltecer essa cultura para tomá-la como referência à identidade cultural espanhola. Esta operação não foi, entretanto, trivial. Em seus romances, Lorca se apóia no imaginário ocidental para então deixar passear sua poesia mítica, que entrelaça mundos em um plano metafórico, sugerindo novas relações entre o elemento nacional eo cigano. 0 utras obras apontam para uma identidadeentrea Espanha e os ciganos, mas na obra de Lorca tal associação se dá de maneira explícita e eminentemente política. Por esse motivo, proponho determo-nos em alguns trechos dos poemas de Lorca, buscando extrair deles 0 que 0 autor considera relevante para pensar a identidade espanhola.

O s ciganos aparecem na poesia de Lorca como personagens de um mundo mítico. É incerto se as referências do mundo sobrenatural (quando, por exemplo, lua e o vento são personificados) são parte da cosmologia dos ciganos ou recursos poéticos. D esta maneira, Lorca suspende o ol har sobre os ciganos para um nível extracotidiano, para um estado em que prevalece a imaginação. A singularidade do texto encontra-se na apresentação de fatos cotidianos - como a briga e o amor- imersos em elementos cósmicos. Por outro lado, sobressai como representação desses ciganos uma certa lei interna, que não diz respeito à sociedade espanhola. A honra éum valor primordial que aparece para avaliar e organizar as relações amorosas e de poder entre ciganos. Em La casada infiel, um cigano narra sua desilusão com a cigana que levara ao rio, pensando que era moça solteira, mas ao saber que tinha marido, é obrigado a mostrar sua honra de "cigano legítimo":

apreciação da representação do cigano na obra de G arcía Lorca sugiro a leitura integral do Romancero gitano, assim como do Poema del cante jondo.

${ }^{12} 0$ romancero é, na literatura espanhola, aquele que canta romances; esses, diferentemente da classifi cação em português, são "composições ao mesmo tempo íntimas e épicas, pessoais e objetivas, narrativas e cheias de diálogo e ação, escritas em octossílabos encadeados pela rima assonante nos versos pares" (Fernandez de los Ríos, 1986:1). 
Y que yo mela llevéal río / creyendo que era mozuela, / pero tenía marido. [... ] / Yo me quité la corbata. / ella se quitó el vestido. / Yo el cinturón con revólver. / Ella sus cuatro corpiños. / [... ] No quiero decir, por hombre, / las cosas que ella me dijo. /

La luz del entendimiento / me hace ser muy comedido. /

Sucia de besos y arena, yo mela llevéal río. / C on el aire se batían las espadas de los lirios. I

M e porté como quien soy. / C omo un gitano legítimo. / La regalé un costurero / grande de raso pajizo, / y no quise enamorarme / porque teniendo marido / me dijo que era mozuela / cuando la llevaba al río (Lorca, [1924-7] 1998: 27-9, grifos meus).

N esse poema a atmosfera onírica abriga uma série de descrições que caracterizam os ciganos. 0 s trechos grifados são particularmente enfáticos na construção de uma identidade masculina. 0 hombre, o gitano legítimo, se afirma por meio do vestuário e do acessório: a gravata e o revólver. N o episódio, o cigano defende-se do perigo de amar uma cigana casada: homem que é, não pode por ela se apai xonar. Esta imagem é ainda mais forte nos poemas "Reyerta" (disputa), "Prendimiento deAntoñito el Camborio en el camino de Sevilla" e "M uerte de Antoñito el Camborio", que descrevem brigas entre dois bandos de ciganos:

En la mitad del barranco / las navajas de Albacete, / bellas de sangre contraria, / relucen como los peces. [... ] / / El juez, con guardia civil, por los olivares viene. I Sangre resbalada gime / muda canción de serpiente. / Señores guardias civiles: / aquí pasó lo de siempre. / H an muerto cuatro romanos / y cinco cartagineses. ("Reyerta")

Antonio Torres $\mathrm{H}$ eredia, / $\mathrm{H}$ ijo y nieto de Camborios, / C on una vara de mimbre / Vaa Sevilla a ver los toros. / [... ] Y a la mitad del camino, / bajo lasramas deun olmo, / guardia civil caminera / lo llevó codo con codo [... ] Antonio, quién eres tú? /

Si tellamaras Camborio, / hubierashecho una fuente/ de sangre, con cinco chorros. / $\mathrm{N}$ i tú eres hijo de nadie, / ni legítimo Camborio. / ¡Se acabaron los gitanos / que iban por el monte solos! / Están los viejos cuchillos/ tiritando bajo el polvo. (Prendimiento de Antoñito... )

Bañó con sangre enemiga / su corbata carmesí, / pero eran cuatro puñalesy tuvo que sucumbir. [... ¿ ¿Q uién teha quitado la vida/ C erca del G uadalquivir? / M is cuatro primos H eredias /

H ijos de Benamejí. / [... ] Y cuando los cuatro primos / llegan a Benamejí, / voces de muerte cesaron / cerca del Guadal quivir

("M uerte de Antoñito... ") (idem, grifos meus).

$M$ ais uma vez as armas - agora a navalha, a faca e o punhal- marcam o universo masculino dos ciganos, junto ao "sangue inimigo", ao "sangue contrário". Ainda, a entrada em cena da justiça espanhola se segue de um distanciamento 
em relação à justiça dos ciganos. 0 juiz observa, de fora, o resultado de uma lei que opera em paralelo, confirmada pela dimensão cotidiana do evento ("aquí pasó lo de siempre"). Em Prendimiento... o autor mostra uma polícia arbitrária, que prende o cigano Antônio Torres Heredia "na metade do caminho". 0 narrador, um cigano onipresente, acusa-o de não ter agido como um "legítimo Camborio", isto é, de não ter matado o guarda civil que o prendeu, fazendo dele uma "fonte de sangue". A voz que lamenta a perda da tradição dos ciganos (" iSe acabaron los gitanos / que iban por el monte solos! / Están los viejos cuchillos / tiritando bajo el polvo") reforça que o lugar da identidade masculina é a honra. A existência desta como definidora do indivíduo e do grupo, entretanto, não é novidade para boa parte do 0 cidente: a honra defendida no duelo entre cavaIheiros, disseminada por exemplo na Europa napoleônica ${ }^{13}$, não é tão distinta das disputas travadas entre ciganos nos poemas de Lorca, sobretudo quando a motivação é uma mulher. D esse modo, creio que ao jogar luz a certos aspectos da moral e da vida dos ciganos, Lorca termina por conformar um imaginário masculino viril ehonrado que serve de paradigma ao espanhol. $\mathrm{H}$ á uma definição nítida das funções masculinas e as femininas, e uma moral rígida que as regula.

No Romancero, as ciganas aparecem freqüentemente associadas à sedução. São, nesse sentido, versões da representação ocidental analisada anteriormente, mas queadmitem uma leitura diversa quando recortadas sob a perspectiva local espanhola. Em La casada infiel, a cigana dissimula seu casamento e seduz 0 cigano, deixando-se levar ao rio. 0 utras duas personagens, a $M$ onja gitana e Preciosa, são retratadas em fantasias sexuais:

Por los ojos de la monja / galopan dos caballistas. / Un rumor último y sordo / le despega la camisa, / y al mirar nubes y montes / en las yertas lejanías, / se quiebra su corazón / de azúcar y yerbaluisa.

Pero sigue con sus flores / mientras que de pie, en la brisa, / la luz juega el ajedrez / al to de la celosía.

(La monja gitana)

Su luna de pergamino / Preciosa tocando viene [... ]

En los picos de la sierra / los carabineros duermen /

Guardando las blancas torres / donde viven los ingleses [... ].

Su luna de pergamino / Preciosa tocando viene /Al verla se ha levantado / el viento que nunca duerme. / San C ristobalín desnudo, Ileno de lenguas celestes, / mira a la niña tocando / una dulce gaita ausente.

${ }^{13}$ Retratados por Joseph Conrad (0 duelo) e Stendhal (0 vermelho e o negro) e também ressignificados pelos western americanos, por exemplo. 
$N$ iña, deja que levante / tu vestido para verte.

Abre en mis dedos antiguos / la rosa azul de tu vientre.

Preciosa tira el pandero / y corre sin detenerse.

El viento-hombrón la persigue / con una espada caliente.

¡Preciosa, corre, Preciosa, / que te coge el viento verde!

¡Preciosa, corre, Preciosa! / ¡M íralo por donde viene! [... ]

(Preciosa y el aire)

0 universo feminino é radicalmente separado do masculino em todo 0 Romancero gitano. Como em representações de outras obras literárias, a mulher cigana é erotizada, mas nestes dois casos ela aparece em uma situação passiva na relação com o homem, e não como a mulher sedutora quemanipula os homens ao seu redor. Além disso, em relação às representações analisadas, no livro de García Lorca, o narrador não é o ocidental enfeitiçado que descreve seu objeto de desejo. 0 ocidental - os policiais e os ingleses- está deslocado, fora da cena, deixando todo o foco para Preciosa e o "vento verde".

$\mathrm{N}$ ão há de ser coincidência, por outro lado, o uso do mesmo nome próprio da gitanilla de Cervantes. Lorca escolhe o nome Preciosa ea acompanha de um instrumento musical já conhecido, o pandeiro. 0 autor apropria-se da idéia da cigana-artista que seduz, mas al tera substancialmente o sentido ao radicalizá-lo. Preciosa é decerto objeto de desejo, mas aqui não é o centro de uma roda de locais, e sim de um personagem cósmico, 0 vento que a persegue. 0 "vento verde" pode ser interpretado como um cigano genérico, no qual é a virilidade que dá o colorido $0^{14}$. Se nos outros textos a sedução era um mecanismo de ocultação e se entrevia na descrição absorta das partes do corpo, aqui ela é crua e direta. Lá, um desejo passivo de espectador; aqui, um desejo em ação, que se atira agressivamente contra seu alvo. Todo o Romancero pode ser relido nesta chave que lança mão de elementos do imaginário ocidental sobre os ciganos para reordená-los, invertê-los, radicalizá-los. Com o enaltecimento da cultura cigana, o que Lorca promove é uma reviravolta nos valores que servem de base à identidade espanhola.

A esse respeito colabora o crítico literário Fernández de los Ríos (1986) com uma interpretação do Romancero gitano, mostrando como o título carrega em si a contradição entre cigano e sociedade espanhola: romancero é uma categoria

\footnotetext{
${ }^{14} \mathrm{D}$ e uma maneira geral nesta obra, L orca metaforiza a "ciganidade" pela cor verde. Um de seus versos mais famosos "verde que te quiero verde. / Verde viento. Verdes ramas." deRomance sonámbulo, é exemplar. É curioso, entretanto, que um viajante do século XIX, G eorge Borrow, tenha descrito a tez dos ciganos como "un bello color oliváceo" ([1841] 1932: 52), ou seja, verde oliva.
} 
literária que se consolida no final do século XIV, em forma de cantares. A partir do século XVI, ele passa da expressão oral para a escrita e éabsorvido do âmbito popular pela elite cultural; os grandes poetas espanhóis apropriam-se desse estilo e fundam uma tradição. A imagem do romancero é, portanto, a de um elemento fincado nas profundezas da cultura espanhola, com uma estabilidade enraizada há séculos. Em contraste com o fixo, aparece o gitano, personagem móvel por excelência, nômade, vagante. 0 cigano está em toda parteenão trava compromisso com o território. A oposição entrea significação do romancero ea do gitano fica explícita: o espanhol versus o não-espanhol; 0 entranhado versuso errante; 0 enraizado versus o flutuante. Esse título teria, desta forma, uma ação de síntese do livro, antecipando a dualidade de opostos que está presente na série de poemas. Tal cadeia de antinomias, entretanto, serviu a Lorca para propor uma representação alternativa de seu país, ao ver no cigano a essência de sua cultura.

El libro [Romancero gitano] en conjunto, aunque se llame gitano, es poema de Andalucía; y lo llamo gitano porque el gitano es lo más elevado, lo más profundo, más aristocrático demi país, lo más representativo desu modo y el que guarda el ascua, la sangre y el alfabeto de la verdad andaluza y universal (Lorca apud Gibson, 1998: 212).

É interessante contrapor este discurso do século XX à novela de M iguel de Cervantes, La gitanilla, publicada na Espanha, em 1613. N esse romance curto, narra-se a história da cigana Preciosa, descrita como uma mulher que canta, acompanhada de um pandeiro, edança, seduzindo os homens com sua sensualidade. Preciosa "diz a sorte" às pessoas, e tira moedas de ouro dos nobres da cidade, até que um deles, o rapaz Andrés, se apaixona por ela e decide abandonar sua vida para seguir a dos ciganos, aliás condição para se casar com ela.

[... ] U na desta nación, gitana vieja, [... ] crió una muchacha en nombre de nieta suya, a quien puso [por] nombre Preciosa, y a quien enseñó todas sus gitanerías, y modos de embelecos, y trazas dehurtar. Salió la tal Preciosa la más única bailadora que se hallaba en todo el gitanismo, y la mas hermosa y discreta que pudiera hallarse [... ].Salió Preciosa rica de villancicos, de coplas, seguidillas y zarabandas, y de otros versos, especialmente de romances [... ]

[... ] D e entre el son del tamborín y castañetas y fuga del baile salió un rumor que encarecía la belleza y donaire de la gitanilla, y corrían todos los muchachosa verla, y los hombres a mirarla. Pero cuando la oyeron cantar, por ser la danza cantada, jallí fue ello! Allí si cobró aliento la fama de la gitanilla [...] 
D iferente do texto de Cervantes, em que se intui a identidade entre ciganos e a Espanha, mas, devido ao contexto histórico em que vivia, tal formulação é anulada (Preciosa, a menina dos olhos, no final "desvira" cigana e volta a ser nobre espanhola), a poesia de Lorca sustenta a ciganidade como traço metonímico espanhol. Essa intenção se explicita com os atributos dearistocracia e profundeza da cultura cigana para representar o nacional espanhol. Entretanto, cabe notar que esta éuma das identidades reivindicadas para representar a Espanha. Certamente, em outros movimentos e épocas outras regiões e culturas foram acionadas para representar o país todo. Por sinal, o intuito não é chegar a uma conclusão sobre a identidade espanhola, mas apresentar a existência de uma leitura interessada dos ciganos a partir de um contexto local. Tal identidade entre Espanha (Andaluzia) e os ciganos antecedeu e ultrapassou a Lorca, às fronteiras da Espanha, e se disseminou largamente, como demonstraram as referências de outros autores.

$\mathrm{N}$ os dias atuais, o flamenco étido como música nacional espanhola, ao me nos para não-espanhóis; a imagem da mulher espanhola pintada em cartazes "para turista ver" é fortemente inspirada na cigana Carmen, de Bizet, linda e sedutora que dança e toca castanholas. 0 cigano, por outro lado, érepresentado sob o signo da virilidade, da coragem eda honra, associado também a um outro ícone nacional, 0 torero ${ }^{15}$. Juntas, estas figuras revelam a essência de representação máscula do homem espanhol.

A análise de dois casos particulares tão diversos ${ }^{16}$ fornece a este estudo uma precaução importante diante de uma generalização ocidental. Cada um deles mostra como é possível, a partir de um mesmo conjunto de obras, empreender leituras diferentes segundo a perspectiva que se escol he abordar. Sem contradizer as representações encontradas no âmbito vasto do 0 cidente, tanto o contexto brasileiro como o espanhol realizam interpretações particulares, e cada um deles a seu modo. Embora em ambos casos o horizonte em questão seja a definição de uma identidade nacional, o cigano serve a interesses completamente distintos. N o caso espanhol, busca-se nele o valor do próprio espanhol, pela virilidade do homem, a exuberância da mulher e a arte musical do grupo. No caso brasileiro, tudo ocorre ao contrário; não se reconhece nos ciganos uma qualidade positiva, por contraposição, são as vigarices ea sedução quefazem del es bons análogos do malandro e da mulata, estes sim, ícones nacionais dessa sociedade

${ }^{15}$ Em Andando Sevilha, João C abral já sugerira essa aproximação: “E quando o toureiro é cigano? / Como é que toureava Cagancho // Toureiro e cigano, tinha a arte / de qualquer cigano no baile; [... ]" (M elo N eto, [1987-9] 1995, 667).

${ }^{16} \mathrm{E}$, note-se, interpretadosa partir de materiais diversos: a identidade espanhola via textos literários, a brasileira, usando a crítica literária, isto é, utilizando uma mediação. 
plural e permanentemente oscilante entre a ordem e a desordem. 0 cigano, como signo de alteridade, ao se deixar apropriar de formas tão diferentes, faz prova, nesses exemplos, de ambigüidade essencial.

\section{BIBLIOGRAFIA}

Alencar, José de. [1857] 1975. 0 guarani. São Paulo: Atica.

Antônio de Almeida, M anuel. [1854-55] 1998. M emórias de um sargento de milícias. São Paulo: Klick Editora.

Azevedo, Aluízio. [1890] 1973. 0 cortiço. São Paulo: Ática.

Candido, Antonio. [1970] 1993. "D ialética da malandragem" in: 0 discurso ea cidade. São Paulo: D uas Cidades.

--_-_-_.-. 1974. "A passagem do dois ao três - contribuições para o estudo das mediações na análise literária", Revista de história, ano XXV, vol. L, t. II.

-----------. [1975] 2002. "Literatura - Sociedade", in: Textos de intervenção. São Paulo: Editora 34.

CervantesS., M iguel de[1613] 1989. La gitanilla in: N ovelasejemplares M adrid: Cátedra.

Cortesão, Luiza e Fátima Pinto. 1995. Cidadãos na sombra. Procesos explicitos e ocultos de exclusão. Porto: Ed. Afrontamento.

D a M atta, Roberto. 1978. Carnavais, malandros e heróis. Para uma sociologia do dile ma brasileiro. Río de Janeiro: Zahar.

Fernández de los Ríosy LuisBeltrán. 1986. La arquitetura del humo: una reconstrucción del Romancero gitano de Federico García Lorca. Londres: Tamesis Books Ltd.

Ferrari, Florencia. 2002. U m ol har oblíquo - contribuições para o imaginário ocidental sobre o cigano. São Paulo, Dissertação de mestrado, D epto. Antropologia Social, FFLCH - USP.

García L orca, Federico. [1924-7] 1998. Romancero gitano. Barcelona: Editorial 0 ptima.

Gibson, Ian. 1998. Vida, pasión y muerte de Federico García Lorca (1898-1936). Barcelona: Plaza \& Janés Editores.

Gil Vicente. [1525] 1974. Farsa das ciganas. Lisboa: Sá da Costa.

Ginzburg, Carlo. 1991. "Leprosos, judeus, muçulmanos" e "Judeus, hereges ebruxas" in: H istória noturna - decifrando o sabá. São Paulo: Companhia das Letras.

H ugo, V ictor. [1831] 1975. N otre D ame de Paris. Paris: Gallimard.

Leblon, Bernard. 1990. Los gitanos de España - el precio y el valor de la diferencia. Barcelona: G edisa.

M elo N eto, João Cabral de. [1987-9] 1995. Andando Sevilha in: O bra completa. Rio de Janeiro: N ova Aguilar.

M erimée, Prosper. [1845] 1960. Carmen. Paris: Garnier Frères.

N assar, Raduan. [1975] 1998. Lavoura arcaica. São Paulo: Companhia das Letras.

Schwarcz, Lilia K.M . 1995."C omplexo de Zé C arioca -notas sobre uma identidade mestiça e malandra", RBCS N 029 , out.

Teixeira, Rodrigo C orrêa. 1999. H istória dos ciganos no Brasil. Recife: $N$ úcleo deEstudos Ciganos.

Vaux de Foletier, François de. 1970. M ille ans d'histoi re des tsiganes. Paris: Fayard. 